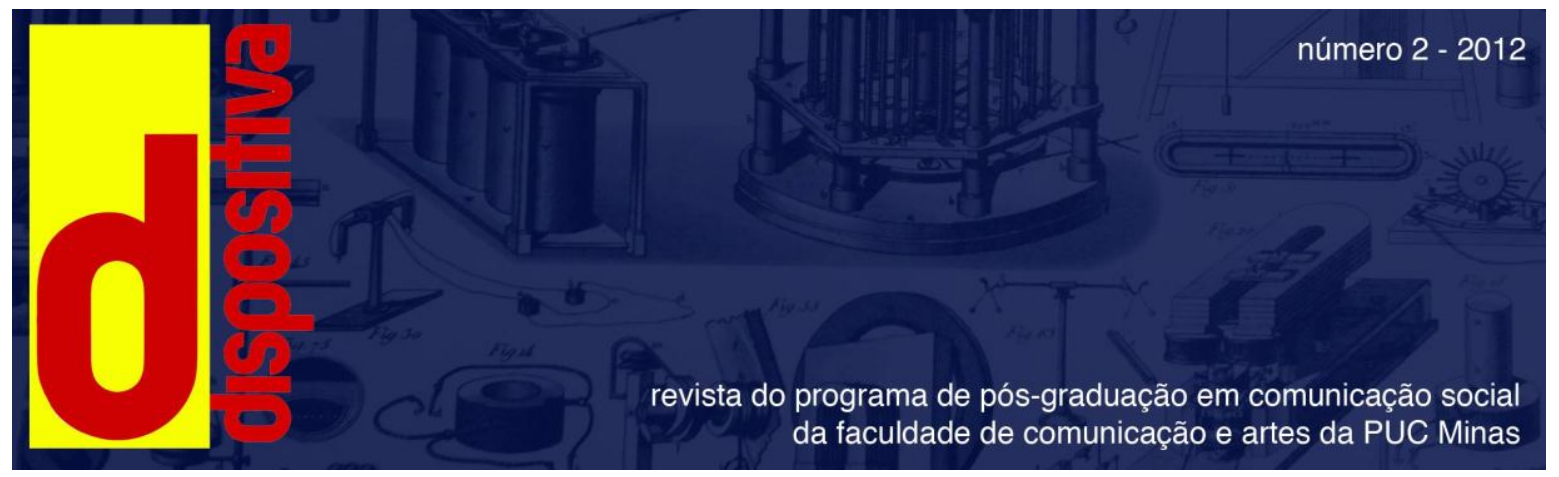

\title{
Comunicação, mulheres e aids: a visibilidade e o seu reverso // Communication, women and AIDS: visibility and its reverse
}

\section{Valdir de Castro Oliveira ${ }^{1}$ e Daniela Savaget Barbosa Rezende 2 \\ Resumo}

Este artigo busca discutir as relações entre o par visibilidade/invisibilidade e a epidemia de aids entre mulheres. Para tanto, faz uso de alguns resultados apontados por uma pesquisa que analisou os sentidos produzidos pelos silêncios presentes no cenário da feminização da epidemia. Trata-se de um trabalho que perpassa o tema da invisibilidade e da própria visibilidade como problemas de saúde e de comunicação, sendo o silêncio uma forma de expressão dessa comunicação e de produção de sentidos sobre a temática. Evidencia, assim, o imbricamento da questão no campo da saúde pública, refletindo diferentes formas do fazer ver apontadas sobre a epidemia ao longo dos anos, e da sua correlação com estigmas e preconceitos presentes no centro da vulnerabilidade social feminina ao HIV e aids.

Palavras-chave: Comunicação e saúde; visibilidade; aids; mulheres.

\begin{abstract}
This article discusses the relationship between the visibility and invisibility and the AIDS epidemic among women. To do so, makes use of some results indicated by a survey that examined the meanings produced by silences presents in the scenario of the feminization of the epidemic. This study understands invisibility and visibility as health problems and communication, and silence is a form of communication and expression of meaning on the subject. Evidence thus the imbrication of the question in the field of public health, reflecting

\footnotetext{
${ }^{1}$ Valdir de Castro Oliveira é professor doutor do Programa de Pós-Graduação em Informação, Comunicação e Saúde do Icict/Fiocruz.

2 Daniela S. Rezende é mestre em Ciências pelo Programa de Pós-Graduação em Informação e Comunicação em Saúde do Icict/Fiocruz.
} 
different ways of view indicated on the epidemic over the years, and its correlation with stigmas and prejudices in the center of female social vulnerability to HIV and AIDS.

Keywords: Communication and health; visibility; AIDS; women.

\section{Introdução}

Este artigo propõe discutir questões referentes ao campo da "comunicação e saúde", mais especificamente a "comunicação e aids", trazendo à tona uma reflexão sobre o par visibilidade/invisibilidade nesse campo. Para tanto, utilizou-se parte dos resultados e apontamentos obtidos a partir de uma pesquisa de dissertação que buscou compreender os sentidos produzidos pelo silêncio entre mulheres vivendo com HIV e aids. A pesquisa foi aprovada pelo comitê de ética indicado pela instituição em que foi desenvolvida.

Ao longo dos anos, diversos atores sociais e instituições tornaram o campo das mídias um espaço propício para a discussão e a produção de sentidos sobre a epidemia de aids, evidenciando diferentes processos do ver referentes à doença. Tais processos se basearam, inicialmente, nos lugares privilegiados dos que detinham a fala sobre o assunto: os atores do campo científico. Por um lado, médicos e pesquisadores valeram-se dos meios de comunicação para divulgar novas informações sobre a aids e, por outro lado, o campo das mídias também se apoiou nesses atores para a produção dos sentidos sobre a doença, uma vez que se trata, conforme reforça Rodrigues (1990), de um campo de mediação capaz de interpelar todos os outros campos.

A anonimidade daqueles que viviam e conviviam com a realidade da doença era, muitas vezes, preservada por tarjas pretas em suas imagens e pelo uso de nomes fictícios. Diariamente, os jornais noticiavam os novos números das "vítimas da aids", associando a doença à morte. Conforme aponta Lima (2006), o mundo vivia não só a epidemia da doença, mas também a epidemia de informações sobre a aids.

As taxonomias, formas de classificação - logo, exercícios de poder - não só relacionaram a aids a um caráter irreversível, como também a associaram a públicos específicos. Os homens criaram "falsas categorias classificatórias" (BASTOS, 2006, p. 30), e os diferentes veículos de comunicação contribuíram para a construção de sentidos sobre a doença a partir da publicação de textos que expressavam essas categorias, introduzindo na sociedade noções estigmatizantes, como os termos "peste gay" e "câncer gay". 
As metáforas e classificações nascidas em meio à chamada "epidemia de informações" sobre a aids fortaleceram o seu reconhecimento como "Doença dos 5H". Hemofílicos, heroinômanos (usuários de heroína injetável), homossexuais, haitianos e hookers (em inglês, prostitutas) formavam o grupo de pessoas com maior risco de contrair o HIV. A hipervisibilidade dada aos "grupos de risco", entretanto, acabou por tornar determinadas populações invisíveis no cenário da epidemia, ao não identificá-las como também vulneráveis à exposição ao vírus da aids.

O desenvolvimento deste trabalho ressalta que este é o caso das mulheres. A relação entre a população feminina e a doença, entendida como restrita às parceiras de usuários de drogas injetáveis (UDI), de hemofílicos e de homens bissexuais, ou às mulheres envolvidas com a prática da prostituição, retardou o início das primeiras respostas coordenadas sobre a epidemia para a população feminina (BRASIL, 2007). O cenário revela a correlação entre a visibilidade e o cuidado, uma vez que o atual contexto político, econômico e cultural da sociedade é marcado pela dependência dos dispositivos de informação, conforme reforça o trecho: "Se eu não sou reconhecido, não existo para as políticas públicas, não me comunico nem se comunicam comigo, não apareço em lugar nenhum, não recebo cuidado. Eu sou negligenciado, eu adoeço.” (ARAÚJO, MOREIRA, AGUIAR, 2011, p. 11). Os autores ressaltam, entretanto, que a visibilidade por si só não garante o cuidado, porém, no campo da comunicação e saúde, o reconhecimento é "uma das principais dimensões do problema, é também evidência" (ARAÚJO, MOREIRA, AGUIAR, 2011, p. 11).

Difícil não reconhecer, ainda, a relação entre o par visibilidade/invisibilidade e as questões referentes ao silêncio entre mulheres vivendo com HIV e aids. Por um lado, é possível observar as mulheres soropositivas para o HIV invisíveis no cenário da epidemia graças às questões classificatórias e, por outro lado, a invisibilidade se dá pelo silenciamento público da doença, que também retorna ao cenário das estigmatizações retratadas pelo campo das mídias especialmente nas décadas de 1980 e 1990. Tal silenciamento reflete questões referentes ao preconceito, remetendo à hipervisibilidade dada à doença desde o seu surgimento, num ciclo caricato de relações de poder entre a sociedade. A imagem pré-concebida das pessoas vivendo com HIV e aids, relacionada a questões estigmatizantes e classificatórias, acaba por obscurecer a individualidade das mesmas e, assim, torná-las invisíveis para a sociedade. 


\section{Bases teóricas do método}

O método proposto na pesquisa que serve de base para este artigo articulou diferentes técnicas de metodologia qualitativa, que juntas permitem pensar a comunicação distante da ideia de simples transferência de informação, visão ainda predominante no campo da saúde.

A partir da análise de discursos das observações e de entrevistas de mulheres vivendo e convivendo com HIV e aids que se reúnem na organização não governamental (ONG) Pela Integração e Valorização do Doente de Aids (Pela Vidda) no Rio de Janeiro, foi possível pensar a questão da visibilidade/invisibilidade entre mulheres vivendo com HIV e aids e a sua correlação com o silêncio. A própria questão visibilidade/invisibilidade foi uma das categorias da análise proposta, cujo eixo estruturante é dado pela Semiologia dos Discursos Sociais, ou Teoria Social dos Discursos. Tal teoria entende os fenômenos sociais como fenômenos de produção de sentidos, ou seja, a significação é percebida como resultado das estratégias discursivas dos sujeitos (PINTO, 1999). Vale ressaltar que, ainda que na prática da análise as categorias se entrelaçarem, é sob a questão visibilidade/invisibilidade que o artigo se detém.

A Semiologia dos Discursos Sociais vê, assim, a comunicação como um espaço de negociação, no qual os discursos são produzidos, circulam e são consumidos (PINTO, 1999). Nesse cenário, evidencia-se a necessidade de enfocar as ausências, os silêncios e entender melhor os mecanismos de silenciamento (ORLANDI, 1997). Logo, o par visibilidade/invisibilidade aqui apresentado possui uma conotação política e cultural, repercutindo no planejamento, efetivação e avaliação das políticas nacionais de saúde. Desse modo, considera-se o termo visibilidade sob a perspectiva social, na qual a invisibilidade reflete diferentes manifestações de um sofrimento político, impedindo que muitas pessoas infectadas pelo vírus HIV possam se manifestar publicamente. Entende-se, assim, que a visibilidade e a invisibilidade caracterizam-se enquanto dimensões sociais da epidemia da aids.

\section{Discursos (in)visíveis}


Fazendo uma retrospectiva é possível perceber que muito já se discutiu e ainda se discute sobre aids. Desde a sua classificação, em 1982 nos Estados Unidos, a doença foi tema de diversas publicações na imprensa internacional e nacional, desencadeando uma busca constante no meio comunicacional por informações sobre a enfermidade.

Ao longo dos anos, várias semantizações no campo das mídias foram feitas pelo corpo social: agentes sociais e instituições construíram sentidos sobre a doença através dos diferentes discursos produzidos, e se mantiveram no centro das relações de poder referentes à realidade da epidemia. Diariamente, epidemiologistas, religiosos, ativistas e indústria farmacêutica valeram-se da função mediadora da mídia entre o indivíduo e o coletivo, revelando uma disputa de forças sociais sobre a temática.

Os discursos referentes à aids muitas vezes se mostraram repletos de metáforas e classificações, trazendo à tona maneiras de discriminar. Termos como "peste gay" e "câncer gay", assim como outras metáforas relacionadas à doença, tal qual "grupo de risco", foram sendo expressos nos veículos de comunicação. Assim, à medida que a doença foi ganhando destaque no campo das mídias, sua construção de sentidos realizava-se (FAUSTO NETO, 1999).

Em meio a essa construção da realidade da epidemia no Brasil através dos discursos arquitetados pelos veículos de comunicação, comunidades afetadas direta ou indiretamente pelo HIV também buscavam visibilidade no campo: em 1985 nasciam as primeiras ONGs dedicadas exclusivamente à aids e em 1986 foi criado o Programa Nacional de Doenças Sexualmente Transmissíveis e Aids (PN-DST/AIDS).

A integração dessas entidades consagrou o Brasil como modelo internacional no combate à epidemia. Ainda assim, mesmo diante das conquistas, conflitos ainda são revelados por discursos repletos de taxonomias. Ao longo dos anos, além de associaram a aids a um caráter irreversível (câncer, peste, síndrome), elas também a relacionaram a públicos específicos, especialmente os homossexuais masculinos. Segundo Lima (2006), tal fato acabou evitando e/ou amenizando, a correta avaliação dos riscos de transmissão da doença.

No Brasil, o primeiro caso de aids foi classificado também em 1982, data em que se adotou o nome "Doença dos 5H". Os casos notificados da doença foram, assim, sendo classificados dentro dos chamados "grupos de risco", que incluíam os homossexuais, 
hemofílicos, haitianos, heroinômanos e hookers. Ainda nos anos 1980, o termo "grupo de risco" foi substituído por "comportamento de risco", devido às mudanças ocorridas no curso da epidemia, mas ainda centrando-se na ideia de risco assumido por uma decisão individual.

Com o tempo, o conceito de risco individual cedeu espaço para a noção de vulnerabilidade social, abrangendo questões relacionadas ao comportamento coletivo. Mudanças nas expressões referentes à aids estão relacionadas ao fato da epidemia ter declinado entre homo/bissexuais e registrado um aumento proporcional de casos entre heterossexuais de menor faixa etária, entre segmentos com baixa escolaridade e entre o sexo feminino, a chamada feminização e heterossexualização da aids (BRASIL, 2007).

\section{Vulnerabilidade ao HIV/aids}

Conforme apontado, o termo vulnerabilidade tem sido utilizado na literatura científica principalmente após a década de 1980, quando se observam os primeiros casos de aids no Brasil. Além de identificar as situações em que as pessoas correm maior ou menor risco de se exporem à infecção, o termo fornece informações para que cada um perceba se tem maior ou menor chance de se proteger, superando o caráter individualizante e probabilístico do conceito de risco empregado na epidemiologia clássica.

Logo, a vulnerabilidade de certo grupo da sociedade à epidemia é definida pelo conjunto das características econômicas e socioculturais que reforçam ou diluem o risco individual (AYRES et al., 1999). A ideia integra múltiplas dimensões que se articulam em contextos específicos, sejam eles de um indivíduo ou de um grupo social. Todas as pessoas que se expõem a uma relação sexual sem proteção correm o risco de se infectar, entretanto, fatores individuais e coletivos apontam graus variados de vulnerabilidade ao qual cada indivíduo está exposto à infecção pelo vírus.

A infecção pelo HIV se dá pelo contato direto com o sangue, o sêmen e as secreções vaginais, o que pode acontecer no sexo oral, na relação vaginal e no sexo anal. A maior probabilidade de infecção pela mulher pode se dar por diferentes fatores, dentre eles os biológicos, que incluem maior carga viral no esperma; liberação de maior quantidade de secreção sexual masculina durante as relações sexuais; permanência do fluido masculino no canal vaginal em torno de 72 horas; facilidade da entrada do vírus na mulher em casos nos 
quais há ectopia cervical (ferida no útero) e/ou a presença de qualquer DST no homem ou na mulher.

Além de, biologicamente, as mulheres serem mais susceptíveis ao HIV, as formas de poder entre homens e mulheres também acabam por torná-las mais vulneráveis à infecção. Tais formas revelam relações sociais nas quais as mulheres têm dificuldade de negociar o uso do preservativo; de decidir se querem ou não ter relações sexuais; costumam ver o relacionamento amoroso estável como sinônimo de imunização; não dialogam com seus companheiros sobre questões referentes à própria sexualidade; estão em maior situação de pobreza e violência.

Parker e Camargo Júnior (2000) lembram que, no Pais, as desigualdades explicam as diferentes vulnerabilidades ao HIV/aids. Para os autores:

[...] a vulnerabilidade diferencial afeta mulheres diferentes de modo diverso, dependendo de outros fatores estruturais, ou seja, que mulheres pobres são mais vulneráveis que as que não o são, que as mulheres pobres jovens são mais vulneráveis que as mais velhas pertencentes ao mesmo estrato, que as mulheres pobres jovens sem alternativas econômicas viáveis além do trabalho com sexo são mais vulneráveis do que aquelas que dispõem de outras opções econômicas (PARKER, R.; CAMARGO JÚNIOR, K. R., 2000, p.98).

Tentando reduzir as vulnerabilidades que atingem as mulheres no Brasil, foi lançado, em 2007, o Plano integrado de enfrentamento à feminização da epidemia de aids e outras DSTs (BRASIL, 2007). Segundo o Plano "a razão de sexos vem diminuindo sistematicamente, passando de 15,1 homens por mulher em 1986, para 1,5 homens por mulheres em 2005" (BRASIL, 2007, p. 10).

Somada a essa conjuntura, verifica-se ainda a pauperização da aids, crescente incidência da epidemia junto às camadas com baixa renda e baixo nível de instrução, mais uma questão de invisibilidade relacionada à doença. Quanto menor a escolaridade, maior o percentual de infectados pelo vírus da aids (BRASIL, 2007).

\section{A aids entre mulheres: epidemia que não se vê}

Na visibilidade, dispositivos midiáticos constituem e são constituídos pelo público por meio do confronto de vozes (RODRIGUES, 1990). A partir dessa ideia sobre a visibilidade é possível perceber que, por um lado, ela tem surtido um efeito positivo frente à epidemia de aids, já que a disponibilidade de informações permite à sociedade tomar conhecimento do agravo e evidenciar lutas por combate à injustiça social; e por outro lado 
um efeito negativo, por visibilizar pessoas infectadas pelo HIV, atraindo para elas um conjunto de preconceitos e estigmas. Por isso a presença do silêncio nesse cenário, se revelando como uma tática frente a um quadro social negativamente imposto às mulheres vivendo com HIV e aids. Logo, entende-se que a visibilidade se dá na medida em que acontecem situações em que a revelação da pessoa vivendo com HIV e aids se torna evidente no enfrentamento da sua nova realidade e a invisibilidade nesse cenário se fundamenta no não revelado (o silêncio e o silenciamento sobre a condição sorológica positiva ao HIV, por exemplo).

O histórico de hipervisibilidade dada à doença repercutiu e ainda repercute negativamente em alguns aspectos sobre a própria doença, por exemplo, ao projetar sobre a pessoa soropositiva para o HIV um estigma que a constitui enquanto estereótipo. O estigma corresponde a uma forma de preconceito e acaba por gerar um efeito contrário ao da visibilidade, pois "dissolve a identidade do outro e a substitui pelo retrato estereotipado e a classificação que lhe impomos” (SOARES; BILL; ATHAYDE, 2005, p. 175).

Trata-se de mais uma questão da invisibilidade entre mulheres vivendo com HIV e aids que é reforçada por históricos de mulheres silenciadas pela relação patriarcal brasileira, na qual componentes socioeconômicos e culturais estruturam as desigualdades entre homens e mulheres. O trecho a seguir reforça tal perspectiva: "A maioria dos diagnósticos relativos às mulheres se mantém diretamente vinculada ao parceiro comunicante e poucos são os dados sociodemográficos a respeito dessas mulheres. Ou seja, elas permanecem sem história e socialmente anônimas" (GUIMARÃES, 2001, p. 29).

A partir do exposto sobre a visibilidade no campo da comunicação e aids entre mulheres, é possível pensar as faces do seu reverso, a invisibilidade. Resumidamente, elas encontram-se relacionadas a:

- “Grupos de risco". Mais tardiamente identificadas como uma população também vulnerável à exposição ao HIV, as mulheres ficaram invisíveis no contexto da epidemia. Parker e Galvão (1996) destacam a predominância, mesmo quando as associações simbólicas entre aids e homossexualismo começaram a dar lugar a relações mais complexas, da associação entre risco pela contaminação pelo HIV e a masculinidade. De encontro a tal constatação, Tomazelli (2001) verifica que o conceito de risco ainda conduz à subnotificação ou atraso de notificação nos casos de aids em mulheres no Brasil. Nesse 
sentido, as mulheres que se identificam, ou são identificadas por profissionais de saúde como pertencentes a tal grupo tendem a ser diagnosticadas mais cedo. De acordo com a autora, a maioria das mulheres com diagnostico tardio possui relacionamentos conjugais estáveis, refletindo a falsa ideia de que esse perfil de mulher encontra-se mais distante da doença por possuir apenas um parceiro sexual. Assim, a invisibilidade da representação social da aids entre mulheres se manifesta, nesse cenário, como o que não pode ser enxergado.

- Estereótipos. Quando indivíduos são classificados como integrantes de um determinado grupo suas individualidades são dissolvidas e, consequentemente, sua visibilidade social. No caso das pessoas vivendo com HIV e aids, a doença, pelo histórico de construção derivada de condutas pecaminosas, projeta um estigma que as anula. $\mathrm{O}$ estigma, afirmam Soares, Bill e Athayde (2005), corresponde a uma forma de preconceito, logo, a uma forma de invisibilidade. Segundo eles, no preconceito uma hispervisibilidade oculta a individualidade da pessoa para o estereótipo imposto, assim, todas as suas singularidades desaparecem.

- Marginalização. A pauperização da aids, a violência e a relação de ambas com o cenário das mulheres traz à tona um problema de invisibilidade que pode ser visto como um problema de indiferença. Assim como na invisibilidade provocada pelo preconceito, na invisibilidade como indiferença há a anulação dos indivíduos: a indiferença ignora a presença. Nesse caso específico a invisibilidade refere-se a uma negligência sobre a presença de alguém. Encontram-se, nesse cenário, mulheres excluídas do processo comunicativo e político referente à epidemia, onde se acentuam as desigualdades sociais e econômicas determinantes da saúde e promovem diferentes vulnerabilidades. Contradizem, assim, os princípios de universalidade, equidade e integralidade do Sistema Único de Saúde (SUS). A partir do momento em que o indivíduo não aparece como alguém que age, fala e reflete sobre o mundo, deixa de aparecer como cidadão. O cidadão desaparece para aparecer como integrante de um grupo social marginalizado.

\section{Silêncios estruturantes dos sentidos produzidos por mulheres vivendo com HIV e aids}

As questões referentes à visibilidade/invisibilidade esbarram diretamente na presença dos silêncios como marcas estruturantes dos sentidos produzidos por mulheres 
vivendo com HIV e aids. Essas marcas aparecem de diferentes formas ao longo do percurso de desenvolvimento da epidemia.

No início da epidemia, pode-se observar uma opção pelo silenciamento de pessoas vivendo com HIV e aids na grande mídia, que se refletia sob a negação de uma entrevista. O cenário de silêncios também se expandia para as relações afetivas e de trabalho, nas quais havia uma clara opção pelo silenciamento da condição sorológica positiva para o HIV. Silenciamento este que estava diretamente vinculado às grandes questões classificatórias que a aids trouxe consigo, que apontam um universo repleto de estigmas. Com o passar dos anos, o Brasil aliou esforços do Estado, setor privado e sociedade civil para promover novos diálogos no campo, porém, ainda assim, muitas vezes o silêncio continua a se mostrar presente na sociedade em contextos parecidos aos descritos anteriormente.

Há uma série de fatores que envolvem o universo desse silêncio. Pode-se dizer que as mulheres foram (e de certa maneira continuam) silenciadas pela relação patriarcal brasileira, que estrutura as desigualdades entre homens e mulheres. Entre as mulheres, o silêncio pode ir de encontro a questões muito particulares referentes à sexualidade, área cerrada da sociedade, conforme afirma Foucault (2010).

Logo, o silêncio pode ser tático, uma forma de evitar a dor ou uma resposta encontrada por essas mulheres para um processo negativo a elas imposto, por exemplo, no contexto da sexualidade e dos preconceitos e estigmas em torno da doença em si. Observase, assim, que o silêncio não é o oposto da comunicação, já que exprime sentidos. O procedimento de mostrar uma coisa e esconder outras tem uma conotação política: "o silêncio é assim a 'respiração' (o fôlego) da significação, um lugar de recuo necessário para que se possa significar, para que o sentido faça sentido" (ORLANDI, 2007, p. 13).

Entre o silêncio das mulheres e a (in)visibilidade do vivido no plano assistencial e antropológico-cultural, é possível evidenciar algumas questões. Elas não se esgotam aqui, porém é possível expor colocações sobre as modalidades do silêncio no que se refere ao cenário mulheres vivendo com HIV e aids. São elas:

- As mulheres estão sempre fazendo escolhas entre o dizer e o não dizer que remetem ao tratamento das informações divulgadas pelo campo das mídias, especialmente nas décadas de 1980 e 1990. Informações essas pautadas pela classificação, rotulação e estigmatização dos grupos sociais infectados pela aids. Há, assim, uma clara opção pelo silêncio como 
tática, como forma de evitar tal classificação, rotulação e estigmatização, muitas vezes já sofridas pelas próprias mulheres.

- O silenciamento sobre o "viver com aids" nesse cenário é, assim, parte da experiência da identidade dessas mulheres, pois é o que lhes dá condição de movimento, evitando que sejam vistas como estereótipos do "grupo de risco soropositivo para o HIV", porém, por outro lado, acaba reforçando a invisibilidade da mulher nesse cenário, pela falta de comunicação sobre o tema.

\section{Considerações finais}

$\mathrm{O}$ atual contexto social, político e econômico em que vive toda a sociedade brasileira é marcado pelo excesso de visibilidade. A sociedade vive em uma era congestionada por textos e discursos visíveis pelos dispositivos de comunicação e informação, que permitem diferentes formas de sua produção, circulação e consumo, promovendo novos agendamentos sobre aquilo que é visível e o que não é. Trata-se de um verdadeiro bios midiático, uma "sintaxe universal que feitichiza a realidade e reduz a complexidade das antigas diferenças ao unum do mercado" (SODRÉ, 2002, p. 11).

O cenário da aids não foge a essa realidade. Nele surge a preocupação com aqueles que estão à margem dos processos de interação informacional, por isso possuem pequena possibilidade de serem retratados pela mídia Nesse campo observa-se que, no ceio da epidemia as mulheres foram, como foi possível conferir, invisíveis dentro dos chamados "grupos de risco", e os próprios grupos acabaram por criar noções estigmatizantes capazes de tornar, mas uma vez, as mulheres invisíveis no cenário da epidemia ao projetar sobre elas um estigma que as anula enquanto indivíduos e as constitui enquanto estereótipos.

Soares, Bill e Athayde (2005) referem-se à "cegueira seletiva" quando tratam da invisibilidade no campo social. Para eles, projetar sobre alguém um estigma, um preconceito ou uma negligência é torná-lo invisível. "Quando o fazemos, anulamos a pessoa e só vemos o reflexo de nossa própria intolerância. Tudo aquilo que distingue a pessoa, tornando-a um indivíduo; tudo o que nela é singular desaparece" (SOARES, BILL, ATAHYDE, 2005, p. 175).

Vale ressaltar que os autores advertem, entretanto, que nem toda visibilidade é positiva. A hipervisibilidade de um tema como a aids, por exemplo, pode acabar por iluminar a imagem caricata das pessoas, descrita no parágrafo anterior. Nesse sentido, os 
autores reforçam a diferença entre preconceito e indiferença. Nos dois casos há a anulação da pessoa, mas por meios opostos. Ao contrário da indiferença, na qual a negligencia se dá pela presença de alguém, o preconceito corresponde a uma hipervisibilidade, que ilumina uma imagem pré-construída, obscurecendo a individualidade e singularidade da pessoa.

Seja como for, a invisibilidade repercute na saúde dos indivíduos, inviabilizando a garantia dos princípios doutrinários que regem o SUS. A visibilidade é determinante na construção dos discursos e das diferentes vozes no espaço público no campo da saúde. A hispervisibilidade, entretanto, pode gerar um efeito contrário, que retoma à própria invisibilidade, também repercutindo negativamente na garantia dos princípios do sistema público de saúde brasileiro. Assim, a comunicação entre mulheres vivendo com HIV e aids e, no sentido mais macro, a comunicação em aids necessita entender os silêncios e “amplificar as vozes historicamente abafadas" (ARAÚJO e CARDOSO, 2007). Necessita o reconhecimento das individualidades dos que estão presentes no campo.

\section{Referências bibliográficas}

ARAúJO, I.S.; CARDOSO, J. M. Comunicação e Saúde. Rio de Janeiro: Ed. Fiocruz, 2007.

ARAÚJO, I.S.; MOREIRA, A.L.; AGUIAR, R. As doenças negligenciadas e a comunicação: três afirmações e muitas questões. Montevideo, XI Congresso Latinoamericano de Investigadores de la Comunicación, 2012.

AYRES, J.R.C.M. et. al. Vulnerabilidade e prevenção em tempos de Aids. In: BARBOSA, R. PARKER, R. (organizadores). Sexualidade pelo avesso: direitos, identidades e poder. Rio de Janeiro, Relume Dumará, 1999. p. 50-71.

AYRES, J.R.C.M. et al. Aids, vulnerabilidade e prevenção. Rio de Janeiro, ABIA/IMSUERJ, II Seminário Saúde Reprodutiva em Tempos de Aids, 1997.

BASTOS, F.I. Aids na Terceira Década. Rio de Janeiro, Editora Fiocruz, 2006.

BRASIL. Ministério da Saúde. Secretaria de Vigilância da Saúde. Programa Nacional da DST/Aids, Plano integrado de enfrentamento à feminização da aids e outras DSTs, 2007.

FAUSTO NETO, A. Comunicação e mídia impressa. Estudo sobre a AIDS. São Paulo: Hacker Editores, 1999. 
FOUCAULT, M. A ordem do discurso. Tradução Laura Fraga de Almeida Sampaio. 20 ed. São Paulo, Ed. Loyola, 2010.

GUIMARÃES, C.D., 1929-2000. Aids no Feminino. Por que a cada dia mais mulheres contraem Aids no Brasil? Rio de Janeiro, Editora UFRJ, 2001.

LIMA, C.R.M. AIDS. Uma epidemia de informações. $2^{a}$ ed. São Paulo, Editora Papers, 2006.

ORLANDI, E.P. As formas do silêncio. No movimento dos sentidos. $6^{\mathbf{a}}$ ed. Campinas, Ed. Da Unicamp, 1993.

PARKER, R.; CAMARGO JR., K.R.. Pobreza e HIV/AIDS: aspectos antropológicos e sociológicos. Cad. Saúde Pública, Rio de Janeiro, v. 16, n.1, p. 89-102, 2000.

PARKER, R.; GALVÃO, J. (orgs). Introdução. In: PARKER, R.; GALVÃO, J. (orgs). . Quebrando o Silêncio: Mulheres e Aids no Brasil. Rio de Janeiro, Relume-Dumará: ABIA:IMS/UERJ, 1996. p. 7-15.

PINTO, M.J. Comunicação e discurso. São Paulo, Hacker Editores, 1999.

RODRIGUES, A.D. Estratégias da Comunicação. Lisboa, Editora Presença, 1990.

SOARES, L.E.; BILL, M. V.; ATHAYDE, C. Cabeça de porco. Rio de Janeiro, Objetiva, 2005.

SODRÉ, M. Antropológica do espelho. Rio de Janeiro: Ed. Vozes, 2002.

SONTAG, S. A doença como metáfora. Aids e suas metáforas. Tradução Rubens Figueiredo/Paulo Henriques Britto. São Paulo: Companhia das Letras, 2007.

TOMAZZELI, J. G. Aids e mulheres no Rio de Janeiro: o limite da certeza em duas técnicas complementares de análise. 2001. 133 f. Dissertação (Mestrado em Saúde Pública) - Escola Nacional de Saúde Pública, Fundação Oswaldo Cruz, Rio de Janeiro.

Recebido em: 31 jul.2012

Aprovado em: 17 set. 2012 